Saudi Journal of Oral and Dental Research

Abbreviated Key Title: Saudi J Oral Dent Res

ISSN 2518-1300 (Print) |ISSN 2518-1297 (Online)

Scholars Middle East Publishers, Dubai, United Arab Emirates

Journal homepage: https://saudijournals.com/sjodr

\title{
Utilization of Dental Services in Saudi Arabia: A Review of the Associated Factors
}

\author{
Dr. Saud M Orfali ${ }^{1}$, Dr. Mohammed S Aldossary ${ }^{2 *}$ \\ ${ }^{1}$ Director General, General Directorate of Dentistry, Ministry of Health, Riyadh, Saudi Arabia \\ ${ }^{2}$ Specialist in Pediatric Dentistry, General Directorate of Dentistry, Ministry of Health, Riyadh, Saudi Arabia
}

DOI: $10.36348 /$ sjodr.2020.v05i03.002

| Received: 26.02.2020 | Accepted: 05.03.2020 | Published: 08.03.2020

*Corresponding author: Dr. Mohammed S. Aldossary

Abstract

Oral health services assessment is an ongoing global challenge for improvement of services, quality enhancement and preventing oral diseases. One strategy is to investigate the utilization and access to dental care, and exploring the underlying factors. In Saudi Arabia, only few published studies explored the utilization of dental care services. Hence, this review attempt focusing on the findings of utilization, including manner of use and the associated factors. Only certain possible causes have been studied, and there is limited evidence of the utilization of dental care in Saudi Arabia. Even larger, well-designed studies are needed in order to be a baseline evidence for potential evaluation of progress in dental services after adopting the necessary acts.

Keywords: Dental health service, Oral health, Dental visits, Saudi Arabia, Dental service utilization, Dental care barriers.

Copyright @ 2020: This is an open-access article distributed under the terms of the Creative Commons Attribution license which permits unrestricted use, distribution, and reproduction in any medium for non-commercial use (NonCommercial, or CC-BY-NC) provided the original author and source are credited.

\section{INTRODUCTION}

Dental diseases are considered as a worldwide prominent problem [1]. They are multifactorial and preventable, thus prevention and early detection with management are critical keys toward tackling them. Access to oral health care services is one important approach for the prevention and therapy $[2,3]$.

The access to dental care includes both the availability of services and the desire of the patient to seek the care. Access to and utilization of dental care services are multidimensional principles which are affected by many factors [4].

In Saudi Arabia, both government and private sectors oral healthcare services are provided. All citizens are entitled to complete and free access to oral health care in primary, secondary or tertiary dental clinics of government sector [5].

Globally, inequality in utilization of dental services has been evaluated periodically to determine its extent, to evaluate the underlying factors and to examine any improvements over time [2].

Several studies in various countries showed that the utilization of dental services appears to be unequally distributed among populations and consumers [2].

In Saudi Arabia, only few studies, in limited regions, were conducted to investigate the utilization of dental services and to determine the influencing factors. Furthermore, some studies were conducted on specified target groups.

Thus, this literature review focused on the disparity in the use of dental services in Saudi Arabia in various regions and on the related factors for further studies in the future. This review was performed of published studies conducted in a region in Saudi Arabia between January 2010 and January 2020.

\section{Utilization of dental services in saudi arabia}

In few studies reported in Saudi Arabia, the use of dental services varied among different targeted participants.

The Saudi Health Information Survey by El Bcheraoui et al., found that only $11.5 \%$ of the population of Saudi Arabia over the age of 15 visited dentists for routine check-ups and almost half (48\%) visited dentists during dental problems [6]. The sample size was over 10.000 participants. 
Farsi, in 2010, investigated the utilization of dental services among students, $n=3090$, aged 11-24 years old in Jeddah city, and found only $8.6 \%$ visited dentists for regular check-up. The most common reason to visit the dentist was pain and dental problems $(49.4 \%)$ [7].

On the contrary, Al-Hussyeen in the same year, reported that about $75 \%$ of adolescent females (intermediate students) in Riyadh city, had been visiting the dentist more than once over the last two years, and most of them $(75 \%)$ in private clinics, and $63 \%$ for routine treatment [8]. However, the size of sample $(n=531)$ would affect the results.

Almutlaqah et al., 2018, investigated the utilization of dental services in Abha city, among about 500 adults. About $58 \%$ of respondents were dental services users. Of the participants, $57 \%$ visited dentists during dental emergencies [4].

In another study, Al-Jaber and Da'ar, reported the utilization of dental clinics in Primary Health Care Centers by adults in Riyadh city. In the last 12 months more than half $(53 \%)$ of patients visited a dentist once, $20 \%$ twice, and at least three times (25\%) [9].

Given the limited number of dentists in primary health care facilities, most patients $(77 \%)$ obtain dental treatment in private dental clinics [4,9]. However, insurance status was not investigated which would affect these results. Dental pain (50\%) was the most common reason for visiting a dentist, although regular checkups were counted for only $15 \%$ of participants [9].

In Jazan region, Quadri et al., investigated the utilization of dental services, and found that less than half $(45.8 \%)$ of the sample surveyed indicated that their last visit to a dentist was within a year, and $33 \%$ of them claimed that a dentist should only be visited if they have dental pain [10].

Hamasha et al., explored the utilization of dental care services by elderly people (65 years old and above) in Riyadh city. Only $37 \%$ of participants $(n=350)$ had proper utilization and access to dental care [11].

\section{Factors influencing dental services utilization}

Various studies investigated the association between dental services utilization and some factors (independent variables), such as sociodemographic, socioeconomic and educational variables. Wide variation in participants should be interpreted with caution. Some studies targeted adults or children, or investigated specific groups (e.g., dental students, smokers, pregnant women, medically compromised patients) [2].
A large range of factors beyond those evaluated is affected by inequality or is even underlying the observed differences in utilization. Dental anxiety, for example, has been found to be closely associated with educational position [2].

Some potential barriers to access to dental care would include difficulty in getting appointment, waiting time, feeling that there is no need for treatment, and dental fear $[7,11]$. In addition, marital status could have an effect on the use of dental services, because single participants were more likely to be non-utilizers of dental services than married participants [4].

Regarding the gender factor, dental services utilization was reported to be more in female than male participants [7], which is in agreement with global findings [2,3]. The other studies conducted in Saudi Arabia did not make a comparison between male and female.

\section{Education, Income \& Insurance}

Utilization of dental services was higher in those with higher educational status or income [4,6]. Thus, education and income are significant predictors for the dental services utilization. Patients who are better educated were twice as likely to have regular dental appointments compared to patients who completed their primary education only [10].

Interestingly, the study by Hamasha et al., on elderly people, found no significant correlation between utilization of dental services and participants' education [11]. However, service utilization was higher among those with higher incomes (45\%) compared with those with lower incomes $(31 \%)$. Additionally, in that study, the greatest barrier reported for accessing dental services was a lack of perceived dental needs $(70.2 \%)$ followed by lack of dental insurance (64.5\%) [11].

The likelihood of attending a dental clinic increased with education, among people who have good oral health practice [6].

The high cost of dental care has been the most restricting factor for dental services utilization for those who visited private dental clinics $[8,9]$.

Education and awareness are closely linked to dental literacy and positive oral health habits such as daily tooth brushing or a healthy diet. Therefore, underutilization of dental care services may result from a lack of knowledge, which is therefore perpetuated because oral health education is given in many countries in dental clinics [2].

On the other hand, similar to global results, utilization of dental services in those without insurance cover was lower than in those with such a status $[2,3]$. 
Education and economic status, which are interlinked together and often, decide the financial means of a person. This will have an effect on utilization in countries where dental care is not provided free of charge, especially when one considers the potentially catastrophic impact of dental expenses [2].

\section{Place of Living}

Dental services utilization was reported globally to be lower in those living in rural than those living in urban places [2]. Al-Hussyeen reported that the most discouraging factor was the far geographic location of the dental clinics [8].

Due to either physical access (e.g., lack of transportation), or limited availability of dental services in rural areas, the place of living, rural versus urban, may impact the utilization of dental services. Almutlaqah et al., found that transport difficulties and health-related participants (related to movement difficulties) were the major predictors and barriers to access to dental care [4]. In elderly people, transportation was identified as barriers to dental services by $44.2 \%$ of participants [11].

\section{Quality of Dental Services}

Obviously, meeting patient needs and dental care standards would impact patient behavior in terms of better compliance, less missed appointments and less stress and anxiety. Some studies have indicated disappointment with quality; have been correlated with generally poor compliance with standards for care, low utilization or cessation of treatment $[4,8]$.

Quality of dental care has been found to be the most motivating factor for the use of dental services in private dental clinics [8].

\section{CONCLUSIONS}

- Inequalities in the utilization of dental services are significant and common across the globe, and have consequences for services and health care systems.

- Access to dental care is not a simple issue, and it requires multiple strategies and approaches to address it.

- In Saudi Arabia, more studies are needed to evaluate possible factors associated with inequality, and to assess whether inequalities have increased or deteriorated over time.

\section{REFERENCES}

1. Kassebaum, N. J., Smith, A. G. C., Bernabé, E.,
Fleming, T. D., Reynolds, A. E., Vos, T., ... \& GBD 2015 Oral Health Collaborators. (2017). Global, regional, and national prevalence, incidence, and disability-adjusted life years for oral conditions for 195 countries, 1990-2015: a systematic analysis for the global burden of diseases, injuries, and risk factors. Journal of dental research, 96(4), 380-387.

2. Reda, S. F., Reda, S. M., Thomson, W. M., \& Schwendicke, F. (2018). Inequality in utilization of dental services: a systematic review and metaanalysis. American journal of public health, 108(2), e1-e7.

3. Curi, D. S. C., Figueiredo, A. C. L., \& Jamelli, S. R. (2018). Factors associated with the utilization of dental health services by the pediatric population: an integrative review. Ciencia \& saude coletiva, 23, 1561-1576.

4. Almutlaqah, M. A., Baseer, M. A., Ingle, N. A., Assery, M. K., \& Al Khadhari, M. A. (2018). Factors affecting access to oral health care among adults in Abha City, Saudi Arabia. Journal of International Society of Preventive \& Community Dentistry, 8(5), 431.

5. Alshahrani, A. M., \& Raheel, S. A. (2016). Healthcare System and Accessibility of Dental Services in Kingdom of Saudi Arabia: An Update. Journal of International Oral Health, 8(8).

6. El Bcheraoui, C., Tuffaha, M., Daoud, F., Kravitz, H., AlMazroa, M. A., Al Saeedi, M., ... \& Mokdad, A. H. (2016). Use of dental clinics and oral hygiene practices in the Kingdom of Saudi Arabia, 2013. International dental journal, 66(2), 99-104.

7. Farsi, J. M. A. (2010). Dental visit patterns and periodontal treatment needs among Saudi students. EMHJ-Eastern Mediterranean Health Journal, 16 (7), 801-806, 2010.

8. Al Johara, A. (2010). Factors affecting utilization of dental health services and satisfaction among adolescent females in Riyadh City. The Saudi dental journal, 22(1), 19-25.

9. Al-Jaber, A., \& Da'ar, O. B. (2016). Primary health care centers, extent of challenges and demand for oral health care in Riyadh, Saudi Arabia. BMC health services research, 16(1), 628.

10. Factors influencing Patients' Utilization of Dental Health Services in Jazan, Kingdom of Saudi Arabia

11. Quadri, F. A., Jafari, F. A., Albeshri, A. T., \& Zailai, A. M. (2018). Factors influencing patients' utilization of dental health services in Jazan, Kingdom of Saudi Arabia. International journal of clinical pediatric dentistry, 11(1), 29. 